\title{
Genistein-Derivatives from Tetracera scandens Stimulate Glucose-Uptake in L6 Myotubes
}

\author{
Myung Sun Lee, ${ }^{a}$ Chung Hee Kim, ${ }^{a}$ Duc Manh Hoang, ${ }^{a}$ Bo Yeon Kim, ${ }^{*}, a$ Cheon Bae SoHn, ${ }^{b}$ \\ Mee Ree KIM, ${ }^{b}$ and Jong Seog AHN ${ }^{*, a}$ \\ ${ }^{a}$ Functional Metabolite Research Center, Korea Research Institute of Bioscience and Biotechnology; 52 Eoun-dong, \\ Yuseong-gu, Daejeon 305-333, Korea: and ${ }^{b}$ Department of Food and Nutrition, Chungnam National University; 220 \\ Gung-dong, Yuseong-gu, Daejeon 305-764, Korea. \\ Received September 30, 2008; accepted December 16, 2008; published online December 19, 2008
}

\begin{abstract}
An EtOAc-soluble partition of the MeOH extract of a branch of Tetracera scandens (Dilleniaceae family) was subjected to a glucose-uptake assay, which led to the isolation and identification of five isoflavones of previously known structure namely, genistein (1), its derivatives $3^{\prime}, 5^{\prime}$-diprenylgenistein (2), 6,8-diprenylgenistein (3), derrone (4) and alpinumisoflavone (5). Of these, compounds $2-5$ exhibited significant glucose-uptake activity in basal and insulin-stimulated L6 myotubes. The findings from adenosine monophosphate-activated kinase (AMPK) activation and glucose transport protein4 (GLUT4) and GLUT1 over-expression revealed certain characteristics of compounds $2-5$. These compounds inhibited protein tyrosine phosphatase 1B (PTP1B) activities with $\mathrm{IC}_{50}$ values ranging from $20.63 \pm 0.17$ to $37.52 \pm 0.31 \mu \mathrm{M}$. No muscle cell toxicity was reported with compounds 3-5, while compounds 1 and 2 reduced muscle cell viability with $I_{50}$ values of $34.27 \pm 0.35$ and $18.69 \pm 0.19 \mu \mathrm{M}$, respectively. It was concluded that $T$. scandens and its constituents exerted highly desirable activities on type 2 diabetes mellitus treatment since they significantly stimulated the uptake of glucose, AMPK phosphorylation, GLUT4 and GLUT1 mRNA expressions and PTP1B inhibition in L6 myotubes.
\end{abstract}

Key words Tetracera scandens; isoflavone; diabetes; glucose-uptake; L6 myotube

Natural products are excellent sources of lead compounds in the search for novel drugs for treatment of various diseases. The most under-explored source of such materials lies in the tropical and subtropical regions of the world. In these areas, a long tradition of ethnobotanical medicine often exists and offers a rich and relatively untapped source for the discovery of novel drugs from natural products. ${ }^{1)}$ A traditional Vietnamese medicinal plant, Tetracera scandens is originally from the Quang Ninh province in Vietnam. It is called 'Day Chieu' in Vietnamese and has shown some therapeutic activities in inflammation, hepatitis and gout. ${ }^{1)}$ However, no reports on the effects of $T$. scandens and its components have been published in the field of diabetes.

Type 2 diabetes mellitus (T2DM) is a heterogeneous metabolic disorder characterized by the impairment of insulin-secretion from pancreatic beta cells and insulin resistance in peripheral tissues such as liver, adipose tissue, and skeletal muscle. ${ }^{2)}$ Skeletal muscles account for approximately $75 \%$ of glucose absorption under insulin-stimulated conditions, and a reduction in insulin-stimulated glucose-uptake in skeletal muscles of T2DM patients has been observed both in vitro and in vivo. ${ }^{3,4)}$ Some commonly used glucose-lowering antidiabetic drugs in the market such as metformin, rosiglitazone and pioglitazone are believed to increase the glucose-uptake in skeletal muscle., ${ }^{5,6)}$ Therefore, muscle glucose-uptake could be considered as an excellent target for treatment of T2DM.

Adenosine monophosphate-activated protein kinase (AMPK) plays a central role in the regulation of glucose and lipid metabolism as an intracellular energy sensor. Upon activation by allosteric binding of AMP or phosphorylation at $\mathrm{Thr}^{172}$ of its catalytic subunit, AMPK accelerates ATP-generating catabolic pathways, including glucose-uptake and glucose and fatty acid oxidation. ${ }^{7)}$ In many reports, AMPK-activators such as aminoimidazole carboxamide ribonucleotide
(AICAR), peroxisome proliferator-activated receptor $\gamma$ (PPAR $\gamma$ ) agonists, metformin and berberine stimulated muscle glucose-uptake both in cells and in humans. ${ }^{8-10)}$

Moreover, the uptake of glucose into tissues is mediated to a large extent by the members of a series of facilitated carrier proteins, designated glucose transport protein (GLUT) 1$12 .{ }^{11)}$ GLUT4 is highly expressed in skeletal muscle cells that exhibit regulated insulin-responsive glucose-uptake. The increased expression of GLUT4 has previously been lowered blood glucose and enhanced glucose transport and glucose utilization in skeletal muscles. ${ }^{12)}$ GLUT1 is nearly ubiquitous in its distribution and is thought to be primarily responsible for basal glucose-transport associated with AMPK activation. ${ }^{13,14)}$ The over-expression of GLUT1 in L6 myoblasts and transgenic mice resulted in augmented basal rates of glucose-uptake. ${ }^{15,16)}$ Thus, basal and insulin-stimulated glucoseuptake into skeletal muscle may be regulated at least in part by the level of GLUT1 and GLUT4 expressions in muscle tissue.

Protein tyrosine phosphatase 1B (PTP1B) negatively regulates insulin-signaling, and is strongly involved in glucoseuptake pathways. ${ }^{17)}$ The over-expression of PTP1B in transgenic mice decreased glucose-uptake activity by $40-50 \%{ }^{18)}$ Global deletion of PTP1B in mice results in increased systemic insulin sensitivity, enhanced glucose-uptake into skeletal muscle, and improved glucose-tolerance. ${ }^{19)}$ Hence PTP1B inhibitors are believed to be promising therapeutic agents against obesity and T2DM. ${ }^{20)}$

In the present study, we sought to identify the bioactive constituents of an extract of a branch of $T$. scandens, accounting for muscle glucose-uptake. We also attempted to elucidate the major targets mediating glucose-uptake activities both in basal and insulin-responsive L6 myotubes. Their roles were evaluated by measuring the extent of activation of AMPK, mRNA expressions of GLUT4 and GLUT1, and 
PTP1B activity. Our data collectively suggested that the isolated compounds were potently beneficial in the treatment of diabetes.

\section{MATERIALS AND METHODS}

Cell Line and Reagents L6 rat skeletal muscel cell (CRL-1458 ${ }^{\mathrm{TM}}$ ) was obtained from American Type Culture Collection (ATCC) (Rockville, MD, U.S.A.). Dulbecco's modified Eagle's cell culture medium (DMEM), fetal bovine serum (FBS), horse serum and penicillin/streptomycin were obtained from GIBCO/BRL Life Technologies (Grand Island, NY, U.S.A.). 2-Deoxy-D- $\left[{ }^{3} \mathrm{H}\right]$-glucose was purchased from American Radiolabeled Chemicals Inc. (St. Louis, MO, U.S.A.). PTP1B (human, recombinant) was obtained from BIOMOL International LP (Plymouth Meeting, PA, U.S.A.). Anti-AMPK, anti-P-AMPK and anti-glyceraldehyde-3-phosphate dehydrogenase (GAPDH) were purchased from Cell Signaling (Danvers, MA, U.S.A.). Anti-rabbit horseradish peroxidase-conjugated immunoglobulin $\mathrm{G}$ (IgG) was from SantaCruz Biotechnology Inc. (Santa Cruz, CA, U.S.A.). RNeasy ${ }^{\circledR}$ mini kit was from QIAGEN (Valencia, CA, U.S.A.) and AccuPower ${ }^{\circledR}$ CycleScript RT PreMix (dT20) was from Bioneer Inc. (Daejeon, Korea). Cell Counting Kit8 (CCK8) was purchased from Dojindo Laboratories (Kumamoto, Japan). Other reagents were obtained from Sigma Chemical Co. (St. Louis, MO, U.S.A.).

Plant Material T. scandens were collected at Vietnam in July 2007, and identified by Professor KiHwan Bae. A voucher specimen (No. 07-V001) has been deposited in Korea Research Institute of Bioscience and Biotechnology, Korea.

Extraction and Isolation $T$. scandens $(3 \mathrm{~kg})$ were chopped and extracted three times with $\mathrm{MeOH}$ for $10 \mathrm{~d}$ at room temperature. The extract was evaporated to yield a residue $(410 \mathrm{~g})$. The $\mathrm{MeOH}$ extract was partitioned with $n$ hexane, EtOAc, and $\mathrm{BuOH}$. The active EtOAc $(40 \mathrm{~g})$ phase was separated by silica gel column chromatography $(10 \times 30$ $\mathrm{cm} ; 63-200 \mu \mathrm{m}$ particle size) using a gradient of hexaneEtOAc (from $10: 1 \rightarrow 0: 1$ ) to afford four fractions (\#1-\#4). Fraction \#2 was further purified by HPLC [Optima Pak $\mathrm{C}_{18}$ column, $(25 \times 10 \mathrm{~cm}, \mathrm{RS}$ Tech. Daejon, Korea); a gradient mobile phase $\left(54 \% \rightarrow 100 \%\right.$ ACN in $\left.\mathrm{H}_{2} \mathrm{O}\right)$ detected at $210 \mathrm{~nm}$; flow rate: $2 \mathrm{ml} / \mathrm{min}$ ] to yield compound 1 . Compounds 2, 3, 4 and $\mathbf{5}$ were purified from fraction \#3 by HPLC using acetonitrile-water gradient system [Optima Pak $\mathrm{C}_{18}$ column, $(25 \times 10 \mathrm{~cm})$; a gradient mobile phase $(54 \% \rightarrow 100 \%$ $\mathrm{ACN}$ in $\left.\mathrm{H}_{2} \mathrm{O}\right) ; 210 \mathrm{~nm}$; flow rate: $2 \mathrm{ml} / \mathrm{min}$ ].

Cell Culture Monolayers of L6 cells were grown in DMEM containing $10 \% \mathrm{FBS}$ and penicillin $(100 \mathrm{U} / \mathrm{ml}) /$ streptomycin $(100 \mu \mathrm{g} / \mathrm{ml})$, and cultured in a humidified $5 \%$ $\mathrm{CO}_{2}$ incubator at $37^{\circ} \mathrm{C}$. Cells $\left(1 \times 10^{5} / \mathrm{ml}\right)$ were seeded in 12 well plates and grown to $90 \%$ confluency, and differentiated with DMEM with $2 \%$ horse serum for a week.

Glucose Uptake Assay Differentiated L6 mature myotubes were cultured on 12-well plates, incubated serum-free DMEM for $24 \mathrm{~h}$, and washed with Krebs-Ringer $\mathrm{N}$-(2hydroxyethyl)piperazine- $N$-2' -ethanesulfonic acid (HEPES) (KRH) buffer $\left(120 \mathrm{~mm} \mathrm{NaCl}, 5 \mathrm{~mm} \mathrm{KCl}, 2 \mathrm{~mm} \mathrm{CaCl}_{2}\right.$, $1.5 \mathrm{~mm} \mathrm{MgSO}_{4}, 20 \mathrm{~mm}$ HEPES). After compound treatment for $1 \mathrm{~h}$, cells were added with $200 \mathrm{~nm}$ insulin for $20 \mathrm{~min}$. And the cells were incubated in $\mathrm{KRH}$ buffer containing $1 \mu \mathrm{Ci} 2$ deoxy-D- $\left[{ }^{3} \mathrm{H}\right]$ glucose and $5 \mathrm{~mm}$ glucose for $30 \mathrm{~min}$. The reaction was terminated by placing the plates on ice-cold phosphate buffered saline (PBS). After washing the cells with icecold PBS, the cells were dissolved with $0.5 \mathrm{M} \mathrm{NaOH}$ with $0.1 \%$ sodium dodecyl sulfate (SDS). The activity was determined by liquid scintillation counter.

PTP1B Inhibition Assay The inhibitory effect of compounds on PTP1B enzyme activity was measured by a method described previously. ${ }^{21)}$

Western Blot Analysis L6 myotubes were washed with cold PBS containing $1 \mathrm{~mm} \mathrm{Na} \mathrm{NO}_{4}$. The pellet was suspended in extraction buffer $(10 \mathrm{~mm}$ Tris, $\mathrm{pH} 7.4,150 \mathrm{~mm}$ $\mathrm{NaCl}, 0.5 \%$ NP-40, $1 \mathrm{~mm}$ EDTA, 1\% TritonX-100, $1 \mathrm{~mm}$ PI, $1 \mathrm{~mm} \mathrm{Na}_{3} \mathrm{VO}_{4}$ ), and protein concentration was determined with Bio-Rad Protein Assay Reagent. Equal amounts of protein were subsequently fractionated by $10 \%$ SDS-PAGE and transferred to a polyvinylidene difluoride (PVDF) membrane. The blotter was blocked in 5\% skim milk diluted in TBS containing $0.1 \%$ Tween-20 for $1 \mathrm{~h}$ then incubated with primary antibody, anti-AMPK, anti-P-AMPK and GAPDH ( $1: 1000)$, followed by incubation with anti-rabbit horseradish peroxidase-conjugated IgG $(1: 2000)$ and visualized with enhanced chemiluminescence.

Reverse Transcription-Polymerase Chain Reaction (RT-PCR) L6 myotubes were subjected to total RNA isolation by using RNeasy mini kit. RNA concentrations were determined by measuring absorption at $260 \mathrm{~nm}$ in a spectrophotometer. Aliquots of $1 \mu \mathrm{g}$ of total RNA from each sample were reverse transcribed to cDNA using an AccuPower ${ }^{\circledR} \mathrm{Cy}$ cleScript RT PreMix (dT20) according to manufacturer's instructions from Bioneer Inc. PCR primers used in this study included; GLUT4: 5'-GGG CTG TGA GTG AGT GCT TTC-3' and 5'-CAG CGA GGC AAG GCT AGA-3'; GLUT1: 5'-TGC AGT TCG GCT ATA ACA CC-3' and 5'ACA CCT CCC CCA CAT ACA TG-3'; GAPDH: 5'-TAG ACG GGA AGC TCA CTG GC-3' and 5'-AGG TCC ACC ACC CTG TTG CT-3'.

Cell Viability Assay L6 rat myoblasts were seeded at $5 \times 10^{3}$ cells/well in 96-well microplates and allowed to attach for $24 \mathrm{~h}$. Each compound was added to the medium at various concentrations $(0-75 \mu \mathrm{M})$. After $24 \mathrm{~h}$, cell viability was assessed by Cell Counting Kit8 (CCK8). Briefly, highly water-soluble tetrazolium salt, WST-8[2-(2-methoxy-4-nitrophenyl)-3-(4-nitrophenyl)-5-(2,4-disulfophenyl)-2H-tetrazolium, monosodium salt], produced a orange colored watersoluble product, formazan. The amount of formazan dye generated by dehydrogenases in cells was directly proportional to the number of living cells. CCK8 $(10 \mu \mathrm{l})$ was added to each well and incubated for $3 \mathrm{~h}$ at $37^{\circ} \mathrm{C}$, then cell proliferation and cytotoxicity were assessed by measuring the absorbance at $450 \mathrm{~nm}$ using microplate reader (Dynatech MR700). Three replicated wells were used for each experimental condition.

Statistical Analysis Data were presented as mean of triplicate assays \pm S.D. For statistical analysis of the date for single comparison, the significance between means was determined by $t$-test. $* p<0.05, * * p<0.01$ compared with untreated control; \# $p<0.05$, \# $p<0.01$ compared with insulintreated control. 

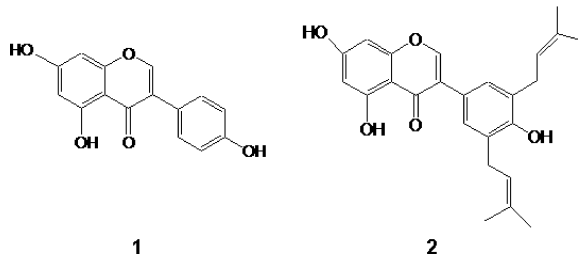

2

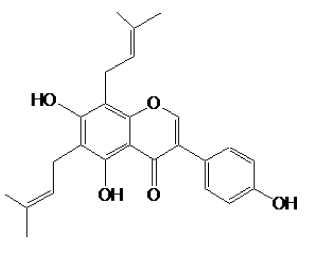

3

Fig. 1. Chemical Structures of Compounds $\mathbf{1}-\mathbf{5}$ Isolated from T. scandens

\section{RESULTS AND DISCUSSION}

In the course of screening of natural medicinal plants using the glucose-uptake analysis, the $\mathrm{MeOH}$ extract of the branches of $T$. scandens was found to significantly stimulate glucose-uptake in basal and insulin-stimulated L6 myotubes $\left(\mathrm{IC}_{50}\right.$ values of $58.14 \pm 0.72$ and $33.62 \pm 0.18 \mu \mathrm{g} / \mathrm{ml}$, respectively). T. scandens, belonging to the Dilleniaceae family, is a Vietnamese traditional medicine whose constituents and effects have not been fully characterized. Here further fractionations and separations by several chromatographic methods yielded five isoflavones from $T$. scandens, and these were identified as genistein (1), its derivatives $3^{\prime}, 5^{\prime}$-diprenylgenistein (2), 6,8-diprenylgenistein (3), derrone (4) and alpinumisoflavone (5) by the direct comparison of their physicochemical and spectroscopic data with those previously reported (Fig. 1). ${ }^{22-24)}$ Isoflavones contained in soy were previously proposed to possess beneficial metabolic effects in patients with diabetes and obesity. ${ }^{25)}$ In this study, we show for the first time that an EtOAc-soluble fraction of $T$. scandens contains isoflavones and has muscle glucose-uptake activity.

To investigate the effects of the isolated compounds $\mathbf{1}-\mathbf{5}$, at various concentrations $(0-25 \mu \mathrm{M})$, a glucose-uptake assay was performed. Incubation of L6 myotubes with compound 1 for $1 \mathrm{~h}$ at all tested concentrations did not enhance the glucose-uptake, whereas compounds $\mathbf{2}-\mathbf{5}$ significantly stimulated the basal and insulin-treated glucose- uptake in a dosedependent manner (Fig. 2). Compound $\mathbf{2}$ was the most active at a lower concentration of $10 \mu \mathrm{m}$, and revealing cytotoxicity at $25 \mu \mathrm{M}$, with increasing basal and insulin-stimulated glucose-uptake of 182.3 and $295 \%$ respectively; compound 3 $(25 \mu \mathrm{M})$ produced an increase of glucose-uptake by 161 and $247 \%$; compound $4(25 \mu \mathrm{M})$ showed a 177 and $285.7 \%$ increase in glucose-uptake; compound $5(25 \mu \mathrm{M})$ produced a 132 and $222 \%$ increase in glucose-uptake. Previously it was shown that compound 1 directly inhibited GLUT4-mediated glucose-uptake in 3T3-L1 adipocytes, ${ }^{26}$ but in this study we did not detect any role of this compound in the regulation of glucose-uptake in L6 myotubes. Theses results indicated that compounds $2-5$ might exert some metabolic roles as glucose-uptake enhancers within skeletal muscle cells.

This study was further extended to determine the modulation of upstream regulators involved in the glucose-uptake signaling pathway such as AMPK, which is an important marker involved in the stage of nutrient-sensing. Phosphorylation of AMPK at $\mathrm{Thr}^{172}$, the active site of the AMPK $\alpha$ subunit and which is essential for enzyme activity, was demonstrated by Western blotting. The levels of AMPK were normalized with glyceraldehyde 3-phosphate dehydrogenase (GAPDH). AMPK was found to have been significantly phosphorylated after the cells were treated with compounds

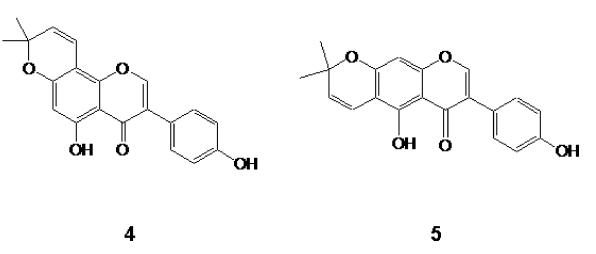

(A)

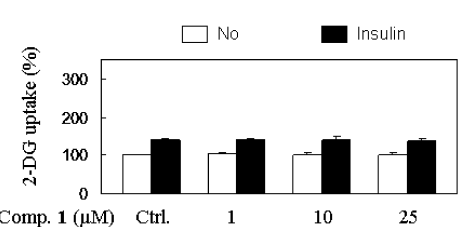

(B)

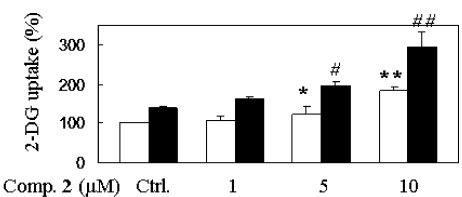

(C)

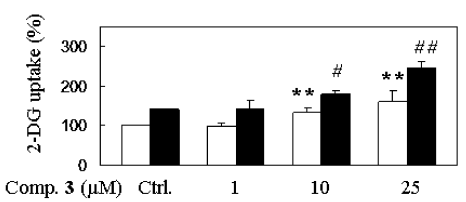

(D)

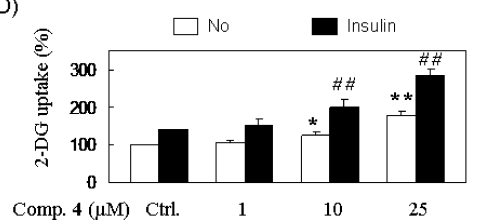

(E)

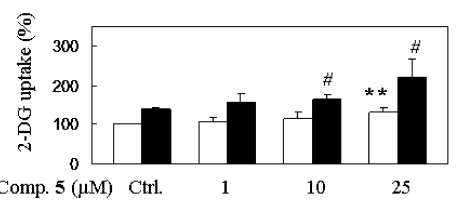

Fig. 2. Basal and Insulin-Stimulated Glucose-Uptake by Compounds $\mathbf{1}-\mathbf{5}$ in L6 Myotubes

The cells were incubated in the presence of $0-25 \mu \mathrm{M}$ compound 1 (A) and 3 (C), 4 (D), 5 (E) and $0-10 \mu \mathrm{M}$ compound 2 (B) for $1 \mathrm{~h}$, and then glucose uptake was assayed. Data are presented as means \pm S.D. of triplicate experiments. Mean value is significantly different $(* p<0.05$ and $* * p<0.01$ as compared with untreated control group; $* p<0.05$ and \# $p<0.01$ as compared with insulin-treated control group).

2-5 $(10 \mu \mathrm{M})$, whereas only a faintly increased level of phosphorylation was observed after treatment with compound $\mathbf{1}$ $(10 \mu \mathrm{M})$ on differentiated L6 myotubes, which are similar to those of glucose-uptake assay (Fig. 3). These results correlated with that of the glucose-uptake assay. Previously, it was suggested that compound $\mathbf{1}$ activated phosphorylation of AMPK to inhibit differentiation of adipocytes ${ }^{27)}$ but no other isolated compounds have yet been reported as AMPK activators. These results implied that AMPK was involved in enhancing the glucose-uptake action of compounds $\mathbf{2}-\mathbf{5}$ in L6 myotubes.

Previous studies showed that highly expressed levels of GLUT4 and GLUT1 increased the insulin-stimulated or basal level of glucose-uptake in both muscle cells and in 


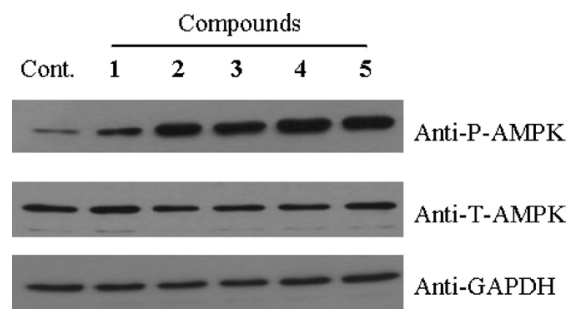

Fig. 3. AMPK Activation by Compounds $\mathbf{1}-\mathbf{5}$ in L6 Myotubes

The cells were treated with $10 \mu \mathrm{M}$ compound $\mathbf{1}-\mathbf{5}$. The cell lysates were analyzed by Western blotting with specific antibodies against total-AMPK and phospho-AMPK $\left(\mathrm{Thr}^{172}\right)$. The protein level was normalized by glyceraldehyde 3-phosphate dehydrogenase (GAPDH).
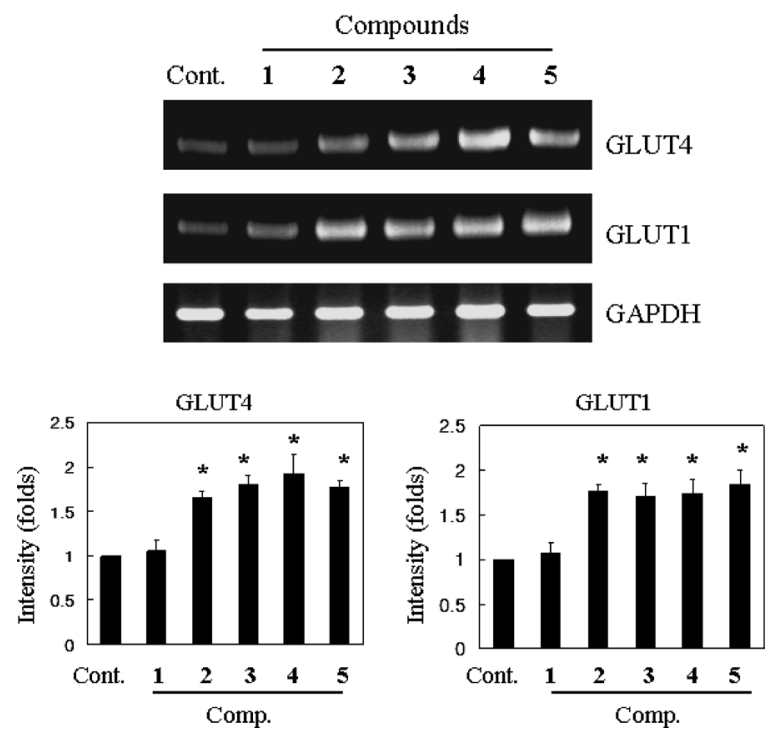

Fig. 4. GLUT4 and GLUT1 mRNA Expression Levels by Compounds $\mathbf{1 - 5}$ in L6 Myotubes

Cells were exposed to compounds $(10 \mu \mathrm{M})$ for $1 \mathrm{~h}$. After washing and lysis, total RNA was isolated and reverse transcribed to cDNA for RT-PCR analysis. Total RNA level was analyzed by GAPDH. Mean value is significantly different $(* p<0.05$ as compared with untreated control group).

mice. ${ }^{12,15,16)}$ To determine whether the difference in expression of GLUT4 and GLUT1 occurred at the level of transcription, an RT-PCR assay was employed. Treatment of L6 myotubes with compounds $\mathbf{2}-\mathbf{5}$ increased the GLUT4 mRNA levels by 1.65-, 1.80-, 1.92-, 1.77-fold, and the GLUT1 mRNA levels by 1.77-, 1.71-, 1.74-, 1.84-fold, respectively, whereas no difference was observed after treatment of the myotubes with compound 1 (Fig. 4). This suggested that the basal and insulin-responsive glucose-uptake into muscle cells treated with compounds $\mathbf{2}-\mathbf{5}$ may be regulated in part by the level of expressions of GLUT1 and GLUT4.

Furthermore, current researchers have demonstrated the possible association of PTP1B in insulin sensitivity with T2DM. ${ }^{28,29)}$ Since PTP1B plays a pivotal role in insulin resistance, the findings of the PTP1B correlates with the glucose-uptake activity of each compound. As shown in Table 1, compounds $\mathbf{2}-\mathbf{5}$ exhibited moderate PTP1B inhibition with $\mathrm{IC}_{50}$ values ranging from $20.63 \pm 0.17 \mu \mathrm{M}$ to $37.52 \pm 0.31 \mu \mathrm{M}$. While no activation of glucose-uptake and AMPK phosphorylation was observed with compound 1 , it showed PTP1B inhibition with an $\mathrm{IC}_{50}$ value of $>80 \mu \mathrm{M}$. Except for compound 5, which was isolated from Erythrina mildbraedii and
Table 1. PTP1B Inhibition Activity of Compounds $\mathbf{1}-\mathbf{5}$

\begin{tabular}{cc}
\hline \hline Compounds & ${\left.\operatorname{PTP} 1 B, \mathrm{IC}_{50}(\mu \mathrm{M})^{a}\right)}$ \\
\hline $\mathbf{1}$ & $>80$ \\
$\mathbf{2}$ & $31.75 \pm 0.27$ \\
$\mathbf{3}$ & $28.13 \pm 0.19$ \\
$\mathbf{4}$ & $20.63 \pm 0.17$ \\
$\mathbf{5}$ & $37.52 \pm 0.31$ \\
Ursolic acid $^{b)}$ & $5.13 \pm 0.45$ \\
\hline
\end{tabular}
a)
rol.

Table 2. Cytotoxic Activity of Compounds $\mathbf{1}-\mathbf{5}$ on L6 Myoblast

\begin{tabular}{cc}
\hline \hline Compounds & $\mathrm{IC}_{50}(\mu \mathrm{M})^{a)}$ \\
\hline $\mathbf{1}$ & $34.27 \pm 0.35$ \\
$\mathbf{2}$ & $18.69 \pm 0.19$ \\
$\mathbf{3}$ & $>60$ \\
$\mathbf{4}$ & $>60$ \\
$\mathbf{5}$ & $>60$ \\
\hline
\end{tabular}

a) Data are presented as means \pm S.D. of triplicate experiments.

formerly proposed to be a PTP1B inhibitor, ${ }^{30)}$ none of the other compounds tested have previously been reported to be PTP1B inhibitors. The findings of this study therefore present compounds $\mathbf{2}-\mathbf{4}$ as novel PTP1B inhibitor compounds, showing some correlation between PTP1B inhibition and insulin-mediated glucose-uptake activity.

Since existing oral diabetic agents have revealed skeletal toxicity, the search for non-toxic diabetic therapeutics has become increasingly important. ${ }^{31)}$ The effect of each compound on muscle cell toxicity was investigated using a CCK8 assay, which measures formazan dye produced by living cells. Compounds $\mathbf{3}-\mathbf{5}$ showed similar results with no toxic effects at concentrations up to $60 \mu \mathrm{M}$ after a $24 \mathrm{~h}$-treatment. However, when cells were exposed to compounds $\mathbf{1}$ and $\mathbf{2}$, muscle cell toxicity was exhibited with $\mathrm{IC}_{50}$ values of $34.27 \pm 0.35$ and $18.69 \pm 0.19 \mu \mathrm{M}$, respectively (Table 2). Previously compound 1 was shown to have anti-proliferative and apoptotic effects on various malignant cell types derived from solid tumors, and even on NIH 3T3 non-tumor cells, ${ }^{32)}$ whereas no cellular cytotoxic effects of compounds $\mathbf{2}-\mathbf{5}$ were reported. The results of the present study indicated that compounds $3-5$ could be possible lead candidates for anti-diabetic drug development without exerting toxicity to muscle cells.

In summary, this is the first study to show that T. scandens and its isoflavones, 3',5'-diprenylgenistein (2), 6,8-diprenylgenistein (3), derrone (4) and alpinumisoflavone (5) stimulate glucose-uptake in basal and insulin-stimulated L6 myotubes in a dose-dependent manner. AMPK activation, GLUT4 and GLUT1 expressions and PTP1B inhibition by bioactive constituents appear to be involved in the mechanism of the stimulation of basal and insulin-responsive glucose-uptake. Thus this study provides evidence that compounds $2-5$ may be possible candidates of a novel therapeutic strategy for T2DM treatment, although further studies will be required to clarify the molecular mechanism of these bioactive constituents.

Acknowledgements This work was supported by the Global Partnership Program (No. M60602000001-06E0200- 
00100) of Korea Foundation for International Cooperation of Science \& Technology (KICOS), the research program for New Drug Target Discovery Program (M107480034607N4800-34610) of Korea Science and Engineering Foundation (KOSEF) through the grants provided by the Korean Ministry of Education, Science \& Technology (MEST) and KRIBB Research Initiation Program.

\section{REFERENCES}

1) Nguyen M. T., Awale S., Tezuka Y., Tran Q. L., Watanabe H., Kadota S., Biol. Pharm. Bull., 27, 1414-1421 (2004).

2) Ward W. K., Beard J. C., Halter J. B., Pfeifer M. A., Porte D., Diabetes Care, 7, 491-502 (1984).

3) Dohm G. L., Tapscott E. B., Pories W. J., Dabbs D. J., Flickinger E. G., Meelheim D., J. Clin. Invest., 82, 486- 494 (1988).

4) DeFronzo R. A., Bonadonna R. C., Ferrannini E., Diabetes Care, 15, 318 -368 (1992)

5) Musi N., Hirshman M. F., Nygren J., Svanfeldt M., Bavenholm P., Rooyackers O., Diabetes, 51, 2074-2081 (2002).

6) Yonemitsu S., Nishimura H., Shintani M., Inoue R., Yamamoto Y., Masuzaki H., Diabetes, 50, 1093-1101 (2001).

7) Ai H., Ihelemann J., Hellsten Y., Lauritzen H. P., Hardie D. G., Galbo H., Ploug T., Am. J. Physiol. Endocrinol. Metab., 282, E1291-E1300 (2002).

8) Cuthbertson D. J., Babraj J. A., Mustard K. J., Towler M. C., Green K. A., Wackerhage H., Leese G. P., Baar K., Thomason-Hughes M., Sutherland C., Hardie D. G., Rennie M. J., Diabetes, 56, 2078-2084 (2007).

9) Sell H., Dietze-Schroeder D., Eckardt K., Eckel J., Biochem. Biophys. Res. Commun., 343, 700-706 (2006).

10) Cheng Z., Pang T., Gu M., Gao A. H., Xie C. M., Li J. Y., Nan F. J., Li J., Biochim. Biophys. Acta, 1760, 1682-1689 (2006).

11) Joost H. G., Thorens B., Mol. Membr. Biol., 18, 247-256 (2001).

12) Gibbs E. M., Stock J. L., McCoid S. C., Stukenbrok H. A., Pessin J. E., Stevenson R. W., Milici A. J., McNeish J. D., J. Clin. Invest., 95, 1512-1518 (1995).

13) Olson A. L., Pessin J. E., Annu. Rev. Nutr., 16, 235-256 (1996).

14) Abbud W., Habinowski S., Zhang J. Z., Kendrew J., Elkairi F. S.,
Kemp B. E., Witters L. A., Ismail-Beigi F., Arch. Biochem. Biophys., 380, 347-352 (2000).

15) Marshall B. A., Ren J.-M., Johnson D. W., Gibbs E. M., Lillquist J. S., Soeller W. C., Holloszy J. O., Mueckler M., J. Biol. Chem., 268, 18442-18445 (1993).

16) Robinson R., Robinson L. J., James D. E., Lawrence J. C., J. Biol. Chem., 268, 22119-22126 (1993).

17) Simoncic P. D., McGlade C. J., Tremblay M. L., Can. J. Physiol. Pharmacol., 84, 667-675 (2006).

18) Zabolotny J. M., Haj F. G., Kim Y. B., Kim H. J., Shulman G. I., Kim J. K., Neel B. G., Kahn B. B., J. Biol. Chem., 279, 24844-24851 (2004).

19) Elchebly M., Payette P. E., Michaliszyn W., Cromlish S., Collins A. L., Loy D., Normandin A., Cheng J., Himms-Hagen C. C., Chan C., Ramachandran M. J., Gresser M., Tremblay L., Kennedy B. P., Science, 283, 1544-1548 (1999).

20) Sun T., Wang Q., Yu Z., Zhang Y., Guo Y., Chen K., Shen X., Jiang H., ChemBiochem, 8, 187-193 (2007).

21) Cui L., Na M., Oh H., Bae E. Y., Jeong D. G., Ryu S. E., Kim S., Kim B. Y., Oh W. K., Ahn J. S., Biorg. Med. Chem. Lett., 16, 1426-1429 (2006).

22) Darbour N., Bayet C., Rodin-Bercion S., Elkhomsi Z., Lurel F., Chaboud A., Guilet D., Nat. Prod. Res., 21, 461-464 (2007).

23) Labbiento L., Menichini F., Delle Monache F., Phytochemistry, 25, 1506-1506 (1986).

24) Singhal A. K., Sharma R. P., Thyagarajan G., Herz W., Govindan S. V., Phytochemistry, 19, 929-934 (1980).

25) Moța M., Gârgavu S., Popa S., Schiopu S., Panduru N. M., Moța E., Rom. J. Intern. Med., 45, 113-121 (2007).

26) Bazuine M., van den Broek P. J., Maassen J. A., Biochem. Biophys. Res. Commun., 326, 511-514 (2005).

27) Hwang J. T., Park I. J., Shin J. I., Lee Y. K., Lee S. K., Baik H. W., Ha J., Park O. J., Biochem. Biophys. Res. Commun., 338, 694-699 (2005).

28) Ukkola O., Santaniemi M., J. Mol. Med., 80, 696-702 (2002).

29) Zick Y., Trends Cell Biol., 11, 437-441 (2001).

30) Na M., Jang J., Njamen D., Mbafor J. T., Fomum Z. T., Kim B. Y., Oh W. K., Ahn J. S., J. Nat. Prod., 69, 1572-1576 (2006).

31) Grey A. B., Ann. Intern. Med., 148, 563-599 (2008).

32) Rucinska A., Roszczyk M., Gabryelak T., Cell Biol. Int., 32, 10191023 (2008). 